\title{
Exploration on Application of High Pressure Water Jet Cleaning Technology
}

\author{
Xinjian $\mathrm{Xu}^{1, *}$, Zhaoxing Meng ${ }^{2}$ and Haiqiang $\mathrm{Lv}^{1}$ \\ ${ }^{1}$ Shandong Xiehe University, Shandong, China \\ 2 Jinan Vocational College, Shandong, China
}

\begin{abstract}
: at present, the three-dimensional cleaning machine involved in tank car cleaning technology in China has full-automatic function, which includes two main structures: three-dimensional positioning machine and high-pressure cleaning machine. However, the tank car cleaning process used in the railway field still has many shortcomings. For example, serious pollution, serious energy consumption, insecurity, etc. In order to improve such defects, it is necessary to introduce new processes and improve the previous cleaning processes. The introduction of new technology can reduce environmental pollution and save capital cost. It can adapt to the development of the times and meet people's needs. Therefore, this paper expounds and analyzes the high-pressure water jet cleaning technology in railway tank cars from the aspects of application and improvement, and puts forward the corresponding improvement measures for reference.
\end{abstract}

\section{Introduction}

Through the installation of the nozzle, the target distance between the nozzle and the inner wall of the tank car can be kept appropriate, and the automatic and efficient cleaning of high-pressure water jet is realized. This kind of new technology and process has been rising rapidly. The core is high-pressure water jet technology. This automatic control system integrates machine, pump and liquid. It has certain advantages in structure, operation and automation, and has reliable and complete product quality, which can make the effect safer, energy-saving and environmental protection.

\section{Overview and technical advantages}

\subsection{Basic overview}

In view of the rapid rise of China's petrochemical industry, petrochemical products tend to be cleaner and large-scale transportation. Railway tank car is its main means of transportation. However, due to the flammable and explosive characteristics of products in the petrochemical field, there are certain requirements for safety factor, pollution degree and cost in the transportation stage.In order to meet the needs of customers and make the tank car have the advantages of cleaning and environmental protection, the tank washing station needs to be designed to clean the internal residues in the process of transportation of petrochemical industry.

At present, there are two operation modes of tank washing process in China. One method is manual cleaning process. That is, traditional steam fumigation, low-pressure fresh water washing and hot air drying. The other method is mechanical cleaning method. Because the former has the disadvantages of small scale, high energy consumption, low efficiency, serious environmental pollution and great personal harm to operators, many large enterprises and petroleum product transfer stations adopt mechanical cleaning method.

\subsection{At present, the main high-pressure water jet cleaning equipment adopts the high-pressure water jet technology during the cleaning of iron tank truck, which is mainly composed of the following core equipment:}

(1) High pressure water supply equipment.It mainly involves water tank, high-pressure water pump, water valve and other equipment.In the process of operation, the industrial water passing through the filter screen will enter the water tank, and the clean water will be brought into the high-pressure water pump by the manual valve or solenoid valve. After the internal water reaches the pressure value of $20 \sim 70 \mathrm{MPa}$ under the action of the highpressure water pump, it can be sprayed to the pipe wall by the high-pressure water pipe and washer, and the internal residues will be hitAfter the action of high-pressure water such as erosion and cutting, the equipment can be cleaned. (2) Clean the equipment.It mainly involves threedimensional crane, cleaning machine and other equipment.These are the core high-pressure water jet cleaning equipment. Dozens of manufacturers at home and abroad have studied and produced such equipment and widely used it in cleaning.

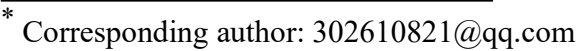




\section{Technical advantages disadvantages}

\subsection{Advantage}

High pressure water jet technology, a cleaning process, originated in the 1970s. It forms the jet through the injection of specific pressure water through the nozzle, can impact and cut the pollutants and rust left in the railway tank car, and can clean the substances left in the tank car.Therefore, the cost saving and environmental protection effect are greatly improved.Compared with the previous cleaning process, tank car cleaning has the following specific advantages for the use of high-pressure water jet:

(1) Elimination of air pollution.Because it does not need steam operation, there will be no materials left in the tank car volatilized with steam in the air, and the materials left in the tank car treated by the sewage plant are washed down by high-pressure water. Therefore, it can provide better working environment for workers and keep the atmosphere healthy.

(2) Efficient washing and irrigation.For the use of highpressure water jet technology during washing and irrigation, generally speaking, it takes $40 \mathrm{~min}$ to clean a vehicle and $60 \sim 70 \mathrm{~min} / \mathrm{set}$ to clean a slightly more difficult tank car.The use of high-pressure water jet technology in the washing and irrigation stage can improve the car washing capacity of each washing station by $4 \sim 5$ times.

(3) Significantly reduced habitual energy consumption and cost.For the use of high-pressure water jet technology in the washing and irrigation stage, the water and power consumption of each unit are $4 \sim 6 \mathrm{~T}$ and $140 \mathrm{~kW} \cdot \mathrm{h}$ respectively. Compared with steam tank washing, it achieves more than $90 \%$ energy-saving effect, and each unit is reduced by $700 \sim 800$ yuan.

\subsection{Defect}

(1) The height is not matched.For the production of $11 \mathrm{~m}$ high and $2 \mathrm{~m}$ wide three-dimensional crane in a unit, if the washing and irrigation station wants to transform the original steam car washing technology through the installation of high-pressure water jet cleaning equipment during washing and irrigation, it can not be realized.This is because this kind of washing and irrigation station has a plant $7 \sim 9 \mathrm{~m}$ high and a platform more than $1 \mathrm{~m}$ wide.

(2) Uneven cleaning quality makes it impossible to clean point by point.If the cleaning machine produced by a unit can control the three-dimensional cleaning head of the arc motion track, the three-dimensional cleaning head in the tank car will spray water on the arc, and all points inside the tank car will be subject to different flushing intensities. (3) Serious waste of high-pressure water.The use of four point cleaning by a unit, that is, the three-dimensional cleaning head in the tank car cleans at each point inside. The dwell time at each point is a few minutes. There is also the problem of uneven cleaning. Only part of the high-pressure water can be effectively used, and the other part is ineffective.

\section{Transformation scheme}

The high-pressure cleaning machine relates to the main components such as travel switch, frame, counterweight and rocker arm. The elbow end connected to the threedimensional cleaning nozzle is $\mathrm{C}$-shaped. Through the action of the feed reducer on the horizontal rocker arm, the $\mathrm{C}$-shaped elbow can be sent into the tank car. Through the simultaneous control of its travel through the switch and program, the three-dimensional cleaning nozzle in the tank car can be cleaned at four points.After unilateral cleaning of the tank car, it is necessary to rotate the horizontal feeder $180^{\circ}$, and then clean the other side of the tank car.Through the automatic extraction of oily sewage by relevant institutions, the pumping sewage can be automatically transmitted to the bottom of the tank car through stainless steel pipe. The external pipe for pumping oily sewage can extract the oily sewage and sewage after installing the joint.The high-pressure cleaning machine involves explosion-proof equipment such as instrument junction box and distribution box.

\section{Transformation design}

\subsection{Design content}

In the process of cleaning, the c-bend can rotate $90^{\circ}$ under the action of motor and a series of deceleration measures, and then the c-bend swings under the action of reducer.In the process of sending the three-dimensional cleaning nozzle, it is necessary to stop at four points for cleaning.During cleaning, the number of cleaning points to stay and the cleaning time of each point shall be set based on the actual demand; If the motor and a series of deceleration measures are used to reverse $180^{\circ}$ rotation of the C-shaped elbow after cleaning one end of the tank car, it is necessary to ensure that the three-dimensional cleaning nozzle has returned to the tank mouth on the $\mathrm{C}$ shaped elbow, and then clean the other end of the tank car.After cleaning the tank car, for the $90^{\circ}$ reverse rotation of the $\mathrm{C}$-shaped elbow, it is necessary to ensure that the three-dimensional cleaning nozzle has returned to the tank mouth on the C-shaped elbow, raise the threedimensional positioning machine to the original position, and prepare for cleaning the next tank car.The water pressure in the cleaning system can reach $34.5 \mathrm{mpa}$ and theoretically reach the flow of $110 \mathrm{~L} / \mathrm{min}$. The eccentric setting of the three-dimensional cleaning nozzle to the two nozzles is mainly used to spray high-pressure water. After the force couple is formed, it can rotate the nozzle. The gear transmission fixed on the nozzle shaft can rotate the shell of the three-dimensional cleaning nozzle.Therefore, the water column can be sprayed in all directions in the tank.By feeding the three-dimensional cleaning nozzle in the horizontal direction, the movement of the threedimensional cleaning nozzle in the tank car can always be kept near the center line. Through accurate positioning, the clean water can be saved, the energy can be used efficiently, the cleaning speed and cleanliness can be improved, and the cleaning of the tank car that is difficult to clean can be realized. 


\subsection{Working principle and process}

High pressure jet and robot are the core technologies of this technology.Its subsystems include high-pressure cleaning system and automatic control system.Its core system is the high-pressure cleaning system, which involves flood device, high-pressure pump and highpressure cleaning machine.In the process of water supply, the water supply device can reach a pressure of 20 $30 \mathrm{MPa}$ through the pressurization of the high-pressure pump. Under the high pressure, the cleaning machine can spray water into the inner wall of the tank car together with the three-dimensional washer. The internal residues can clean the equipment after being hit, eroded, cut and other high-pressure water.

\subsection{Process description}

After the tank car that has not been cleaned reaches the designated position under the traction of the locomotive, if there are many residues in the tank car in winter and the residues have serious icing, it is necessary to heat them with steam first, and then extract the residues; Finally, it can be cleaned.

After cleaning, waste water can be pumped into the sewage tank through the use of vacuum pump. When the water level in the tank is equal to the preset liquid level, or after cleaning a tank truck, it is necessary to automatically open and close the solenoid valves of the compressed air pipeline and vacuum pipeline respectively, and turn off the vacuum pump, and then the sewage pressed into the tank is treated by the sewage treatment system.

After the cleaning of the first and second tank cars is completed, the tractor shall pull them to the next two positions for cleaning. After the tank car is cleaned and the tank cars at the upper two stations are cleaned, it can be towed to the next two stations for drying, and the tank cars cleaned at the upper two stations can be towed to this station for cleaning. The dried tank car is towed to the next two platforms for supplementary drying and inspection. After applying this technology to the tank washing stations of the three companies, the car washing efficiency is greatly improved. For general original light oil tank cars, the actual cleaning time of a single car is shortened to 12 $\sim 15 \mathrm{~min}$, and the maximum daily cleaning capacity of one bench is 15 vehicles; At the same time, the energy consumption, environmental pollution and personal harm to workers are greatly reduced, and the economic and social benefits are very obvious.

\section{Suggestions and application prospects}

In terms of economic and social benefits, this technology is a practical new technology worthy of vigorous promotion. Compared with the latest technical progress at home and abroad, the system can also be improved in three aspects: first, increase the advanced treatment facilities of tank washing sewage, reuse the treated purified water and save water; Second, metal mechanical drying facilities are adopted to avoid the fiber falling into the tank car during the drying process of the canvas air duct, resulting in secondary pollution, and improve the drying efficiency of the tank car; Third, adopt mature, reliable and economical oil and gas recovery technology to further reduce air pollution.

In China, there are tank car cleaning operations in railway, petroleum, petrochemical and chemical enterprises. Most of the existing tank washing stations in China still use the method of manual car washing. Moreover, in the railway system, due to the maintenance of tank cars and the external cleaning of tank cars, energy waste and environmental pollution are very serious. If the existing tank washing stations are reconstructed, the economic and social benefits will be considerable.

\section{Conclusion}

In order to improve the defects of tank car cleaning process, it is necessary to introduce the new process and improve the previous cleaning process. The introduction of new technology can reduce environmental pollution and save capital cost. It can adapt to the development of the times and meet people's needs. Therefore, this paper puts forward the improvement scheme of high-pressure water jet cleaning technology for reference.

\section{Acknowledgments}

This work was financially supported by Scientific Research Projects of Shandong Higher Education Institutions (J18KB043).

\section{References}

1. State Administration of quality and technical supervision. Tsgr0005-2011 safety and Technical Supervision Regulations for mobile pressure vessels [S]. Beijing: Xinhua press, 2011

2. Zhang Dongliang, Chao daiqing. Measures and effects of energy conservation and emission reduction in tank car cleaning [J]. Equipment and corrosion protection, 2010,38 (4): 329-332

3. Li Jie, Li Duomin, Hou lailing. Current situation and development trend of industrial cleaning in China [J]. Guangdong chemical industry, 2008 (12): 69-70

4. Liu tingcheng, fan Xiaohong. Application of high pressure water jet cleaning equipment [J]. China Equipment Engineering, 2013, 02:8-10

5. Zhou Yawen, Xu Baocai, Han Fu. Application status and development trend of industrial cleaning technology in China $[\mathrm{J}]$. China washing products industry, 2010, 01:33-36

6. Cheng Zhixue, Jiang Dianhong, sun Yongjun. Railway tank car cleaning robot $[\mathrm{P}]$. Chinese patent: ZL 200610092305.5, 2007-2-28

7. Shen Wendong, Song Fei. Application of high pressure water jet cleaning technology for railway chemical tank cars [J]. Chemical design, 2004, 14 (2), 26-28.

8. He Mingchao. Selection and application of railway tank car cleaning technology [J]. Engineering technology, 2015 (8), 17. 
9. Li Shu. Application of high pressure water jet technology in cleaning railway tank cars $[\mathrm{J}]$. Cleaning world, 2004 (5) , 16-20. [4] Xu Xiaoxia, Xu Bin. Effects of occupational exposure to amino and nitro compounds of benzene on human health [J]. Occupation and health, 2000 (3), 12-13

10. Shen huanghong, Zhang Gang, Zhang Yifu, etc Overview of potassium nitrate production unit with an annual output of $20 \mathrm{kt}$ Progress in chemical industry, 2002 (7): $506 \sim 508$

11. Compiled by the Editorial Committee of chemical engineering manual Handbook of Chemical Engineering (2) Beijing: Chemical Engineering Publishing house, Beijing: 1989

12. P. L. Kaye . Investigation of Erosion Processes as Cleaning Mechanisms in the Removal of Thin Deposited Soils[J]. America: Wear,1995, 186( 8) : $413 \sim 420$

13. M. C. Leu. Mathemtical Modeling and Experimental Verification of Stationary Water Jet Cleaning Process[ J] . America: Journal ofManu facturing Science and Engineering, 1998, 120(8) : 571 579

14. Shen Zhonghou Water jet theory and technology [M] Dongying: University of Petroleum Press, 1999

15. Zhang Lanfang, Fei Jianguo Mechanism and parameters of dirt cleaning by high pressure water jet [J] Chemical cleaning, 1997,13(5):6 9

16. Chen Yufan, Xu Xiaodong On the improvement of cleaning efficiency of high pressure water jet $[\mathrm{J}]$ Beijing: Chinese Journal of safety science, 1999, 9 (Supplement): $36 \sim 40$ 